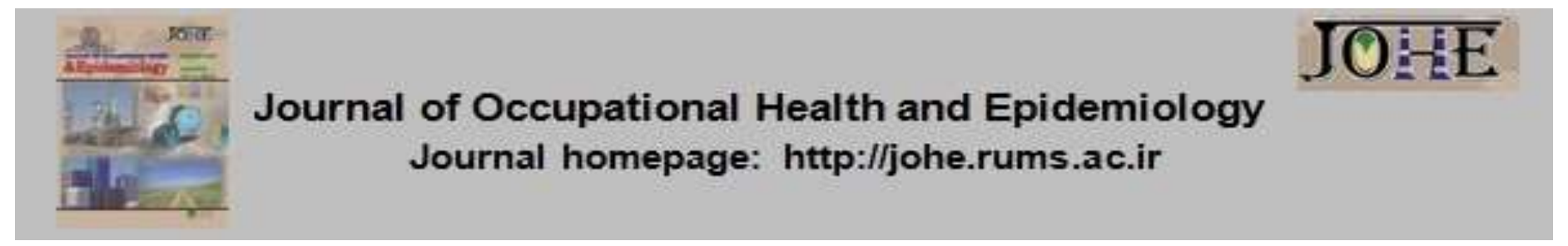

\title{
The Association between Organizational Commitment and Quality of Services Offered to Nurses by a Hospital: A Descriptive-Correlational Study
}

\author{
Yaser Moradi ${ }^{1}$, Rahim Baghaei ${ }^{2}$, Alireza Rahmani ${ }^{1}$, Farzin Mollazadeh $^{3^{*}}$ \\ 1-Assistant Prof., Patient Safety Research Center, Urmia University of Medical Sciences, Urmia, Iran. \\ 2-Associate Prof., Patient Safety Research Center, Urmia University of Medical Sciences, Urmia, Iran. \\ 3-MSc, Patient Safety Research Center, Clinical Research Institute, Urmia University of Medical Sciences, Urmia, Iran.
}

\section{Article Info}

* Corresponding author:

Farzin Mollazadeh,

E-mail:

Farzin.nurse@gmail.com

Article history

Received: Dec 2019

Accepted: Feb 2020

10.29252/johe.9.1.35

Print ISSN: 2251-8096 Online ISSN: 2252-0902

Peer review under responsibility of Journal of Occupational Health and Epidemiology
Citation: Moradi Y, Baghaei R, Rahmani A, Mollazadeh F. The Association between Organizational Commitment and Quality of Services Offered to Nurses by a Hospital: A Descriptive-Correlational Study. JOHE 2020; 9(1):35-40.

\section{Abstract}

Background: Organizational commitment is of considerable importance to nurses working to maintain, restore, and promote human health. One of the factors associated with organizational commitment is the quality of services offered to nurses by hospitals. The present study aims to determine the relationship between organizational commitment and the quality of services offered to nurses by hospitals.

Materials \& Methods: This descriptive-correlational study was conducted in 2017. A total of 150 nurses working at Seyed al-Shohada Heart Center in Urmia were enrolled in this study using a census. Data collection was conducted using a demographic questionnaire, Allen and Meyer's Organizational Commitment Scale, and Ashill's Scale of Service Delivery Performance. In addition, data were analyzed by descriptive statistics and the Pearson's correlation coefficient using SPSS V.16.0, Chicago, Illinois.

Results: The results indicated that organizational commitment was at a moderate level among $67.3 \%$ of the nurses, and the quality of services offered by the hospital to $72 \%$ of the nurses was determined as relatively high. Moreover, the overall score of organizational commitment was found out to be linearly and significantly correlated with the overall score of the quality of services offered to nurses by the hospital as well as all of its dimensions $(r=0.474, p=0.05)$.

Conclusions: There appeared to be a significant positive correlation between the quality of services offered to nurses by the hospital and organizational commitment. Therefore, hospital authorities could improve the quality of services provided to nurses, thereby promoting their organizational commitment. This will in turn lead to an improvement in patient care.

Keywords: Work Engagement, Nurses, Hospitals

\section{Introduction}

Organizational commitment, as a great incentive, could play a significant role in providing high quality healthcare services so that motivated and committed employees exert a profound impact on improving the quality of services [1, 2]. This concept is the degree of an individual's psychological attachment to the organization in which they are employed [3]. Organizational commitment is one of the major variables affecting employee performance, productivity, as well as service delivery and quality [4].

It includes three components of affective commitment, continuance commitment, and normative commitment among which affective commitment is the first and foremost component. Affective commitment is defined as an employee's positive emotional attachment to an organization, which is correlated with organizational justice, job 
performance, and job satisfaction, thereby boosting employee confidence and preventing job abandonment [1,5]. The second component is normative commitment which refers to the level of commitment that an employee feels obligated to stay in an organization and to put considerable effort into the job. Normative commitment inspires employee loyalty towards an organization, which is an important factor in stimulating employee participation in organizational affairs [6, 7]. The third component is continuance commitment which refers to an employee's desire for staying with an organization due to the costs of losing organizational membership or gains from staying with the organization [8].

The presence of committed manpower could reduce absenteeism, delay, and relocation. In addition, it could lead to a significant improvement in organizational performance, high employee morale, and better attainment of major organizational goals $[9,10]$. In the health sector, nurses are the largest group of healthcare providers who directly affect the quality of healthcare services [11]. The success of an organization is undoubtedly linked with the physical and psychological efforts of its human resources [12]. However, it is worth noting employee behavior is a reciprocal response to the behaviors and support they receive from the organization and its managers [13]. In new managerial perspectives, the internal environment of an organization is like a market in which employees (internal customers) receive services, while the organization and its managers are service providers. Against this background, if nurses (internal customers) receive high quality services from an organization and its managers, their attitudes and behavior towards the organization will change [14]. It is held that the provision of services to external customers, i.e. patients, should start with offering high quality services to internal customers, i.e. nurses and other staff. This is due to the fact that the employees of an organization are both receivers and providers of services, so the quality of internal services offered to them exerts a great impact on their behavior shown and quality of services provided to others $[13,15]$. The major mission of hospitals is to provide high quality health services and facilities to patients and to fulfill their needs and expectations [16]. The ultimate objective of all nursing activities is to maintain, restore, and promote human health, so the lack of committed nurses poses many problems on this way and affects the quality of hospital services offered to care receivers $[11,13]$. Given the importance of this issue, the present study aims to determine the relationship between organizational commitment and the quality of services offered to nurses by hospitals (QSONH).

\section{Materials and Methods}

Prior to starting the study, ethical approval was sought and granted by the Ethics Committee of Urmia University of Medical Sciences under approval code IR.UMSU.REC.1394.264. All participants were firstly briefed on the study objectives and methodology. Next, informed consent forms were obtained from all of them before the study. In addition, they were assured that the information obtained would be kept confidential, and that it would be published based on ethical considerations.

This descriptive-correlational study was conducted in 2017 aimed at determining the relationship between organizational commitment and the QSONH. For this purpose, a total of 150 nurses working at Seyed al-Shohada Heart Center in Urmia were enrolled in the study using a census. The inclusion criteria consisted of (a) having practical nursing certifications and/or relevant degrees in nursing, (b) having at least one year of work experience, (c) having been employed in clinical units, (d) being willing to participate in the study, and (e) having no history of mental illnesses. The exclusion criteria included (a) submitting an incomplete questionnaire and (b) withdrawing from the study. To collect data, the researchers attended the research location in the three work shifts of morning, evening, and night. Given the nurses' tight schedule, the questionnaires were distributed among them at the beginning of the shift and collected at the end of it. Data collection tools included a researcher-made demographic questionnaire, Allen and Meyer's Organizational Commitment Scale (AMOCS), and Ashill's Scale of Service Delivery Performance (ASSDP).

The researcher-made demographic questionnaire was made up of variables, including age, gender, educational status (degree), and years of experience.

The AMOCS included 24 items in the three subscales of affective, continuance, and normative commitments. This scale was scored on a sevenpoint Likert scale (from strongly disagree $=1$ to strongly agree=7), with the total score having ranged from 24 to168. The three levels of organizational commitment were low (24-56), moderate (56-102), and high (>102) based on the total score. The AMOCS is a standard and reliable questionnaire employed in several health-related 
studies. The CVI (Content Validity Index) for this scale was reported higher than 0.89 [17, 18].

The ASSDP was used to measure the quality of services provided to healthcare workers. This instrument includes 47 items in 10 aspects, including customer service orientation of the health provider, employee rewards, customer service training, empowerment, teamwork, role ambiguity, organizational commitment, service recovery performance, intent to resign, and extrinsic job satisfaction. A five-point Likert scale was used for scoring each statement in this instrument, which ranged from strongly agree $=5$ to strongly disagree $=1$. The total scores of 160 to 235,90 to 160 , and less than 90 indicated the high, relatively high, and low quality of services offered to the staff by the hospital. This scale was designed by leading management experts around the world with high validity and reliability. The face validity of the instrument was assessed and verified by five faculty members of the School of Nursing and Midwifery. In addition, the reliability of the instrument was approved using Cronbach's alpha $(r=0.93)$.
Data were analyzed using descriptive statistics, a measure of central tendency, the index of dispersion, and the Pearson's correlation coefficient. All statistical analyses were conducted using SPSS V.16.0, Chicago, Illinois. In addition, a p-value of less than 0.05 was considered statistically significant.

\section{Results}

Based on the results of the present study, $84.7 \%$ $(n=127)$ and $15.3 \%(n=23)$ of the nurses were female and male, respectively. Besides, $2 \%(n=3)$ of the participants were practical nurses, $90 \%$ $(n=135)$ had a BSN (Bachelor of Science in nursing), and $8 \%(\mathrm{n}=12)$ had an MSN (Master of Science in nursing). In terms of the participants' age, $12 \%(n=18), 30 \%(n=45), 21.3 \% \quad(n=32)$, and $36.7 \%(n=55)$ of them were in the age ranges of 20-25, 26-30, 31-35, and over 35, respectively. Moreover, 32\% ( $n=48), 20.7 \% \quad(n=31), 26.7 \%$ $(n=40)$, and $20.7 \%(n=31)$ of the participants had a work experience of 1-5, 6-10, 11-15, and over 15 years, respectively.

Table 1. Frequency distribution of the organizational commitment and quality of services offered to nurses working at Seyed al-Shohada Heart Center, Urmia, 2017

\begin{tabular}{|c|c|c|}
\hline Variable & Level & Frequency (percent) \\
\hline \multirow{3}{*}{ Organizational commitment } & High & $48(32)$ \\
\hline & Moderate & $102(67.3)$ \\
\hline & Low & $1(0.7)$ \\
\hline \multirow{3}{*}{$\begin{array}{l}\text { Quality of services offered to nurses by the } \\
\text { hospital }\end{array}$} & High & $40(26.6)$ \\
\hline & Relatively high & $108(72)$ \\
\hline & Low & $2(1.4)$ \\
\hline
\end{tabular}

According to the results of this study, 32\%, 67.3\%, and $0.7 \%$ of the participants experienced high, moderate, and low organizational commitment. Furthermore, the results of data analysis showed that the QSONH was high, relatively high, and low by $26.6 \%, 72 \%$, and $1.4 \%$ among the nurses, respectively (Table 1 ).

Table 2. The assessment of the correlation between the components of organizational commitment and dimensions of the quality of services offered to nurses working at Seyed al-Shohada Heart Center, Urmia, 2017

\begin{tabular}{lcccccccc}
\hline & $\begin{array}{c}\text { Components of organizational } \\
\text { commitment }\end{array}$ & \multicolumn{2}{c}{$\begin{array}{c}\text { Affective } \\
\text { commitment }\end{array}$} & $\begin{array}{c}\text { Continuance } \\
\text { commitment }\end{array}$ & \multicolumn{2}{c}{$\begin{array}{c}\text { Normative } \\
\text { commitment }\end{array}$} & \multicolumn{2}{c}{ Total score } \\
\cline { 2 - 11 } & $\mathbf{r}$ & $\mathbf{p}$ & $\mathbf{r}$ & $\mathbf{p}$ & $\mathbf{R}$ & $\mathbf{P}$ & $\mathbf{r}$ & $\mathbf{P}$ \\
\hline Customer service orientation & 0.235 & 0.004 & 0.207 & 0.011 & 0.115 & 0.161 & 0.264 & 0.001 \\
\hline Employee rewards & 0.287 & 0.0001 & 0.89 & 0.281 & 0.271 & 0.001 & 0.287 & 0.0001 \\
\hline Training & 0.192 & 0.018 & 0.085 & 0.302 & 0.118 & 0.149 & 0.183 & 0.025 \\
\hline Empowerment & 0.340 & 0.0001 & 0.036 & 0.658 & 0.362 & 0.0001 & 0.320 & 0.0001 \\
\hline Teamwork & 0.286 & 0.0001 & 0.142 & 0.082 & 0.266 & 0.001 & 0.312 & 0.0001 \\
\hline Role ambiguity & 0.431 & 0.0001 & 0.017 & 0.835 & 0.331 & 0.0001 & 0.347 & 0.0001 \\
\hline Organizational commitment & 0.576 & 0.0001 & 0.241 & 0.003 & 0.409 & 0.0001 & 0.561 & 0.0001 \\
\hline Service recovery performance & 0.137 & 0.094 & 0.206 & 0.011 & 0.117 & 0.153 & 0.214 & 0.008 \\
\hline Intent to resign & 0.408 & 0.0001 & 0.168 & 0.040 & 0.337 & 0.0001 & 0.412 & 0.0001 \\
\hline Extrinsic job satisfaction & 0.399 & 0.0001 & 0.119 & 0.165 & 0.281 & 0.001 & 0.346 & 0.0001 \\
\hline Total score & 0.477 & 0.0001 & 0.191 & 0.019 & 0.379 & 0.0001 & 0.474 & 0.0001 \\
\hline
\end{tabular}


The assessment of the correlation between the two variables of the study indicated the overall score of organizational commitment was linearly and significantly correlated with the overall score of the QSONH and all its dimensions $(P=0.0001)$. Moreover, affective commitment was linearly and significantly correlated with the overall score of the QSONH and all its dimensions $(P<0.05)$, except service recovery performance $(P=0.094)$. Besides, continuance commitment was linearly and significantly correlated with four dimensions of the QSONH, including customer service orientation, organizational commitment, service recovery performance, and intent to resign $(\mathrm{P}<0.05)$. Furthermore, there was a linear and significant correlation between normative commitment and all dimensions of the QSONH $(P<0.05)$, except customer service orientation, service recovery performance, and customer service training $(P>0.05)$ (Table 2).

\section{Discussion}

In this study, the organizational commitment level was moderate in over half of the nurses (67.3\%). This result was consistent with those of a study by Nabizadeh et al (2013) on the assessment of the level of organizational commitment in clinical nurses. In their study, more than half of the nurses $(53.5 \%)$ had a moderate level of organizational commitment (5). In contrast, Ahmad et al (2010) found out that the majority of Malaysian nurses $(81.33 \%)$ had a high level of organizational commitment (19). This difference in the results could be due to the cultural differences and different management policies of the two countries on healthcare workers. In the present study, most of the nurses $(72 \%)$ reported the quality of services offered to them by the hospital was relatively high. Moradi et al (2014) conducted a study on the quality of work life (QWL) among nurses and its related factors, in which $60 \%$ of the nurses reported they a had moderate level of the quality of work life (20). In contrast, Sharhraky Vahed et al (2011) reported that the majority of nurses were not satisfied with the quality of their work life (21). These differences could be due to the use of different data collection tools. Based on the results of the present study, the overall score of organizational commitment was linearly and significantly correlated with the overall score of the QSONH as well as all of its dimensions, including customer service orientation of the health provider, employee rewards, customer service training, empowerment, teamwork, role ambiguity, organizational commitment, service recovery performance, intent to resign, and extrinsic job satisfaction. Zarei et al (2016) concluded there was a significant positive correlation between organizational commitment and the quality of work life among nurses (22). The results of a study by Akbari Sefedeh et al (2018) on the relationship between organizational commitment and professional commitment in terms of empowering nurses showed that efforts to improve nurses' ability could be a valuable strategy for improving both organizational and professional commitments (23). The results of the abovementioned studies were consistent with those of the present study. Lee et al (2016) studied the effects of perceived organizational justice on empowerment, organizational commitment, and intent to resign. According to their results, upon an increase in perceived organizational justice among nurses, their empowerment and organizational commitment boosted, while their turnover intention decreased. Therefore, nursing institutes and hospitals should adopt more effective HR management measures to improve perceived organizational justice (24). The results of a study by Ouyang et al (2015) showed that job satisfaction in nurses had a significant positive correlation with psychological empowerment and organizational commitment (25). In their study, Nehrir et al (2010) found out there was a significant correlation between job satisfaction and organizational commitment (26). The results of the three abovementioned studies were consistent with those of the present study as well. Barlett KR (2001) concluded there was a significant correlation between training nurses and their organizational commitment. They also reported an increase in training opportunities for nurses would lead to an improvement in their organizational commitment (27). Similarly, Monajati et al (2014) concluded there was a significant correlation between the in-service training of nurses and organizational commitment. Against this backdrop, the need for training nursing staff is becoming more evident (28).

Heidarzadegarr et al (2014) conducted a study on simple and multiple relationships between employee development and organizational commitment. According to their findings, there was a significant positive relationship between the components of employee development, including formal training, teamwork, career, interpersonal communication, and organizational communication as well as organizational commitment. Furthermore, teamwork has been introduced as the major predictor of organizational commitment (29).

Among the limitations of the present study, one could refer to the physical, emotional, and 
psychological status of the participants, which was low due to stress and anxiety caused by heavy workloads during the shifts that could have affected their responses. This problem was partially solved by giving them enough time to fill in the questionnaires from the beginning to the end of their shifts. Refusal on the part of the participants to give some of the required information was possibly due to the relevance of the content of the questions to the management issues of the hospital. This problem was also partially controlled by assuring them of their anonymity in the questionnaires and confidentiality of the information. Another limitation of the present study was that the participants were the nurses of only one hospital. This could have affected the generalizability and external validity of the study to some extent.

\section{Conclusion}

According to the findings of the present study, there is a significant positive correlation between the quality of services offered to nurses by the hospital and their organizational commitment. Organizations always seek to increase efficiency and productivity, with this not being possible without efficient human resources as well as their organizational commitment. To this end, they are requited to improve the quality of services they provide to nurses. Should this occur, they will be able to increase productivity, prevent intent to resign, and reduce job satisfaction, thereby improving organizational commitment.

\section{Acknowledgement}

The present study was extracted from research project no. 1394-01-33-1934 and was funded by the Vice Chancellor for Research of Urmia University of Medical Sciences. We would like to extend our gratitude to the nurses and authorities of Seyed al-Shohada Heart Center and to everybody who assisted us in conducting this study.

Conflict of interest: None declared.

\section{References}

1. Graf E, Cignacco E, Zimmermann K, Zúñiga F. Affective Organizational Commitment in Swiss Nursing Homes: A Cross-Sectional Study. Gerontologist 2016; 56(6):1124-37.

2. Grødal K, Innstrand ST, Haugan G, André B. Affective organizational commitment among nursing home employees: A longitudinal study on the influence of a health-promoting work environment. Nurs Open 2019; 6(4):1414-23.
3. Meyer JP, Herscovitch L. Commitment in the workplace: toward a general model. Human Resource Management Review 2001; 11(3):299-326.

4. Gutierrez AP, Candela LL, Carver L. The structural relationships between organizational commitment, global job satisfaction, developmental experiences, work values, organizational support, and person-organization fit among nursing faculty. J Adv Nurs 2012; 68(7):1601-14.

5. Nabizadeh Gharghozar Z, Atashzadeh Shoorideh F, Khazaei N, Alavi-Majd $H$. Assessing organizational commitment in clinical nurses. Quarterly Journal of Nersing Management 2013; 2(2):41-8.

6. Adeniji AA, Osibanjo AO, Iruonagbe TC, Olawande T, Ibidunni AS, Olokundun MA. From Job Satisfaction to Organizational Commitment: The Mediating Influence of Perceived Treatment of Diversity among Nigeria's Public Healthcare Employees. Open Access Maced J Med Sci 2019; 7(12):2031-5.

7. Abbaszadeh A, Borhani F, Seyedghibi F, Shokouhi M. Organizational Commitment and Its Aspect in Nurses in Hospitals of Shiraz University of Medical Science. Medical Ethics 2013; 7(23):33-46.

8. Akgerman A, Sönmez B. The relationship between trust in first-line nurse managers and organizational commitment. Int Nurs Rev 2020: 67(2):183-90.

9. Zamanzadeh V, Valizadeh L, Neshat $H$. Challenges of human resources management in nursing in Iran: A qualitative content analysis. Nurs Open 2019; 7(1):319-25.

10. Shin S, Park JH, Bae SH. Nurse staffing and nurse outcomes: A systematic review and metaanalysis. 2018; 66(3):273-82.

11. Mudihanselage Hellerawa KSS, Chamaru Adambarage DA. The Nursing Shortage Impact on Job Outcome (The Case in Sri Lanka). Journak of Competitiveness 2015; 7(3):75-94.

12. Ghazi Mirsaeid SJ, Mirzaie M, Haghshenas E, Dargahi H. Human Resources Distribution among Tehran University of Medical Sciences Hospitals. Journal of Payavard Salamat 2014; 7(5):432-46.

13. Allahyari Bouzanjani A, Abbasi A, Alipour F, Khosravaninezhad F. Effect of nurses' perceptions on the quality of services received by managers on their customer-oriented behaviors (patient centered care). Quartely Journal of Nursing Management 2017; 5(3,4):53-61.

14. Pantouvakis A. Internal service quality and job satisfaction synergies for performance improvement: Some evidence from a B2B environment. Journal of Targeting, Measurement and Analysis for Marketing 2011; 19:11-22.

15. Parasuraman A, Zeithaml VA, Berry LL. Servqual: A Multiple-Item Scale for Measuring 
Consumer Perceptions of Service Quality. Journal of Retailing 1988; 64(1):12-40.

16. Madrazo-Pérez $M$, Parás-Bravo $P$, RayónValpuesta E, Blanco-Fraile C, Palacios-Ceña D. The Impact of Health Human Resources Policies in Primary Care Nursing: A Qualitative Study. Int J Envirin Res Public Health 2019; 16(19):3653.

17. Abdul Karim NH, Mohammad Noor NHN. Evaluating the psychometric properties of Allen and Meyer's organizational commitment scale: A cross cultural application among Malaysian academic librarians. Malaysian Journal of Library \& Information Science 2006; 11(1):89101.

18. Naghneh MHK, Tafreshi MZ, Naderi M, Shakeri $N$, Bolourchifard F, Goyaghaj NS. The relationship between organizational commitment and nursing care behavior. Electron Physician 2017; 9(7):4835-40.

19. Ahmad N, Oranye NO. Empowerment, job satisfaction and organizational commitment: a comparative analysis of nurses working in Malaysia and England. J Nurs Manag 2010; 18(5):582-91.

20. Moradi T, Maghaminejad F, Azizi-Fini I. Quality of working life of nurses and its related factors. Nurs Midwifery Stud 2014; 3(2):e19450.

21. Sharhraky Vahed A, Mardani Hamuleh M, Asadi Bidmeshki E, Heidari M, Hamedi Shahraky S. Assessment of the Items of SCL90 Test with Quality of Work Life among Amiralmomenin Hospital Personnel of Zabol City. Avicenna Journal of Clinical Medicine 2011; 18(2):50-5.

22. Zarei E, Ahmadi F, Danshkohan A, Ramezankhani A. The correlation between organizational commitment and the quality of working life among staff of Sarpolzahab health network. Journal of Health Promotion Management 2016; 5(2):61-9.

23. Akbari Sefedeh M, Hashemnia Sh, Rezghi Shirsavar $\mathrm{H}$. The Relationship between Organizational and Professional Commitment to Empower Nurses in Milad Hospital. Journal of Healthcare Management 2018; 9(1):61-72.

24. Lee KE, Kim JH, Kim MJ. Influence of Perceived Organizational Justice on Empowerment, Organizational Commitment and Turnover Intention in the Hospital Nurses. Indian J Sci Technol 2016; 9(20):1-8.

25. Ouyang $Y Q$, Zhou WB, Qu H. The impact of psychological empowerment and organisational commitment on Chinese nurses' job satisfaction. Contemp Nurse 2015; 50(1):80-91.

26. Nehrir B, Ebadi A, Tofighi Sh, Karimi Zarchi AA, Honarvar H. Relationship of job satisfaction and organizational commitment in hospital nurses. Journal of Military Medicine 2010; 12(1):23-6.

27. Bartlett KR. The relationship between training and organizational commitment: A study in the health care field. Hum Resour Dev Q 2001; 12(4):335-52.

28. Monajati SF, Moradi A, Khayeri B. The Relationship between In-Service Training for Nursing Staff Working in Isfahan Medical Sciences University Hospitals and Occupational Outcomes: Organizational Commitment, Job Satisfaction, and Organizational Citizenship Behavior. Iranian Journal of Medical Education 2014; 14(6):495-506.

29. Heidarzadegarr A, Farhang A, Ghorbani M. Simple and Multiple Relationships between Employee Development and Organizational Commitment. Journal of New Approach in Educational Administration 2014; 5(19):43-58. 